\title{
$\beta$-carotene Production of UV-C Induced Dunaliella salina Under Salt Stress
}

\author{
Tassnapa Wongsnansilp ${ }^{1,2}$, Kittisak Yokthongwattana ${ }^{3 *}$, Sittiruk Roytrakul ${ }^{4}$ and \\ Niran Juntawong ${ }^{5}$
}

${ }^{1}$ Interdisciplinary Graduate Program in Bioscience, Faculty of Science, Kasetsart University, Bangkok 10900, Thailand. ${ }^{2}$ Department of Bioscience, Faculty of Science and Fisheries Technology, Rajamangala University of Technology, Srivijaya, Trang Campus, Trang 92150, Thailand. ${ }^{3}$ Department of Biochemistry, Faculty of Science, Mahidol University, 272 Rama 6 Rd., Bangkok 10400, Thailand. ${ }^{4}$ National Center for Genetic Engineering and Biotechnology (BIOTEC), National Science and Technology Development Agency, Pathum Thani, Thailand. ${ }^{5}$ Department of Botany, Faculty of Science, Kasetsart University, Thailand.

\begin{abstract}
Dunaliella salina is an important microalga for $\beta$-carotene production. In Thailand, the $D$. salina has not been commercially cultivated. Aim of this study was to screen high $\beta$-carotene producing mutants. D. salina KU11 cells were radiated with $0.4 \mathrm{mmol}$ photons $\mathrm{m}^{-2} \cdot \mathrm{s}^{-1} \mathrm{UV}-\mathrm{C}$ for $22 \mathrm{~min}$. After 3 weeks, colonies which survived after radiation were allowed to grow on agar plates; fifty colonies out of 19,720 UV-mutagenized strains turned to orange. These colonies were picked up and transfer to modified Johnson medium. Four mutants out of fifty were KU5, KU18, KU20 and KU37 significantly produced high $\beta$-carotene at the stationary phase approximately up to $1.62,2.03,1.32$ and 1.21 folds, respectively, compared to the wild type strain. In all three consecutive cycles of cultivation, the mutant KU18 accumulated 2.4-8.5 folds $\beta$-carotene $(\mu \mathrm{g} / \mathrm{ml})$ and 2.1-4.8 folds $\beta$-carotene $(\mathrm{pg} / \mathrm{cell})$ higher than the wild type, whereas cell density of the mutant KU18 was not different from the wild type. This is the new record of b-carotene producing mutant isolated from saline soil in Thailand.
\end{abstract}

Keywords: Dunaliella salina; UV-C radiation; $\beta$-carotene; high salinity.

*Correspondence: kittisak.yok@mahidol.edu

(Received: 17 January 2019; accepted: 07 February 2019)

Citation: Tassnapa Wongsnansilp, Kittisak Yokthongwattana, Sittiruk Roytrakul and Niran Juntawong, $\beta$-carotene Production of UV-C Induced Dunaliella salina Under Salt Stress, J Pure Appl Microbiol., 2019; 13(1):193-200 doi: 10.22207/JPAM.13.1.20

C The Author(s) 2019. Open Access. This article is distributed under the terms of the Creative Commons Attribution 4.0 International License which permits unrestricted use, sharing, distribution, and reproduction in any medium, provided you give appropriate credit to the original author(s) and the source, provide a link to the Creative Commons license, and indicate if changes were made. 


\section{INTRODUCTION}

$\beta$-carotene is a major carotenoids pigment found in Dunaliella microalgae. The alga could produce $\beta$-carotene under extreme environmental stress, such as high light intensity, high salinity, extreme temperature and $\mathrm{pH}$ or nutrient deficiency ${ }^{1}$. Carotenoids are natural pigments that play pivotal roles in many physiological functions. Carotenoids have also become popular as dietary supplements due to that carotenoids are powerful antioxidants and therefore it can provide protection against ailments, such as cardiovascular diseases, certain cancers, age-related macular degeneration, and neurodegenerative diseases e.g., amyotrophic lateral sclerosis ${ }^{2}$. Recently, microalgae were studied due to their abilities in producing novel bioactive metabolites, including carotenoids that provided health and cosmetic benefits ${ }^{3}$. Carotenoid usage has been studied for long time. However, most focus on carotenoids obtained from several microalgae, vegetables, fruits, and higher plants. In Thailand, cultivation area of D.salina in commercial scale did not widely spread out due to the limit of $\beta$-carotene accumulation in the strain ${ }^{3}$. Genetic improvement of wild species of $D$. salina may play important role on the increase of the $\beta$-carotene content.

UV radiation causes DNA mutation in bacteria, algae and plants, by inducing dimer formation between nucleotide bases, oxidative mutation and generation of several photoproducts that affect replication and transcription of the DNA, causing mutations and death ${ }^{4}$.

UV-C radiation induced mutation of several genera of green algae especially in Chlamydomonadales including Chlamydomonas and Dunaliella. UV-C radiation affected on growth and photosynthesis which resulted in accu-mulation of starch and pigment ${ }^{5,6,7,8}$. Sirikhachornkit et al. ${ }^{8}$, studied utilize of UV-C to isolate Dunaliella mutant. These mutants produced total carotenoid higher than the original wild type did.

Recently, Sharma et al. ${ }^{6}$, presented an approach, using a small dose of UV-C radiation, to rapidly induce unsaturated fatty acids and carotenoid biosynthesis in Dunaliella salina and Haematococcus pluvialis. Total carotenoids and $\beta$-carotene were doubled in $24 \mathrm{~h}$ on $D$. salina when UV-C radiation of $50 \mathrm{~mJ} / \mathrm{cm}^{2}$ was utilized whereas the astaxanthin yield of $H$. pluvialis was increased five times in $48 \mathrm{~h}$ at $30 \mathrm{~mJ} / \mathrm{cm}^{2}$ of UV radiation. This new technique represented a convenient, timesaving and low cost method for commercial microalgal carotenoids production. Moreover Masi \& Melis ${ }^{9}$, reported effect of supplemental UV-B radiation during growth in D.salina was investigated at the cellular level, supplemental UV-B radiation induced a doubling of cell volume, a phenomenon attributed to a slow-down in the rate of cell division. Recently, D. salina was one of algal species which were potentially sources for betacarotene production owing to high commercial value as an anti-oxidant; hence the researches involving $D$. salina were intensively conducted worldwide. However, there was few researches involving $D$. salina studied in Thailand.

Aim of this study was to screen $\beta$-carotene producing strains of Dunaliella salina after UV-C radiation. Growth and $\beta$-carotene production of the mutants was compared to the wild type. We hypothesize that the $\beta$-carotene production in the UV-C mutants is higher than in the wild type strain.

\section{MATERIALS AND METHODS}

\section{Strain and Culture Condition}

Dunaliella salina KU 11 was isolated from saline soil samples collected from the northeastern part of Thailand and was maintained on modified Johnson's medium ${ }^{10}$. The pure culture was grown at $25^{\circ} \mathrm{C}$ under continuous illumination of $50 \mathrm{mmol}$ photons $\mathrm{m}^{-2} \cdot \mathrm{s}^{-1}$ cool-white fluorescent light. This wild type strain was sub-cultured every 15 days. Mutagensis by UV-C and Mutant Screening

For UV-C mutagenesis, the Dunaliella salina KU 11 was prepared to the density of $5^{\prime} 10^{6} \mathrm{cells} / \mathrm{ml}$. Cells were then spread onto $1.5 \%$ agar plates and kept in the dark for $2 \mathrm{~h}$, and were exposed to $0.4 \mathrm{mmol}$ photons $\mathrm{m}^{-2} \cdot \mathrm{s}^{-1} \mathrm{UV}-\mathrm{C}$ irradiation for $22 \mathrm{~min}$, petri disc was wrapped in aluminum foil for overnight to prevent lightinduced DNA repair. Cell were grown at $50 \mathrm{mmol}$ photons $\mathrm{m}^{-2} \cdot \mathrm{s}^{-1}$. After three weeks, when cells started to turn orange, they were selected for the further study.

\section{Growth and pigment accumulation in wild type and mutants}

Fifty mutants were obtained from the 19,720 colonies, from the previous study, and colonies were grown in modified Johnson's medium containing $1.5 \mathrm{M} \mathrm{NaCl}$ under light intensity 
$200 \mathrm{mmol}$ photons $\mathrm{m}^{-2} \cdot \mathrm{s}^{-1}$

KU18 the mutant which provided the highest $\beta$-carotene was selected to culture for three consecutive cycles compared to the wild type (KU11). Algae were grown in modified Johnson's medium containing $2.5 \mathrm{M} \mathrm{NaCl}$ and $0.5 \mathrm{~g} / \mathrm{KNO}_{3}$ under light intensity $200 \mathrm{mmol}$ photons $\mathrm{m}^{-2} \cdot \mathrm{s}^{-1}$ for 14 days.

Cell number was counted every 2 days using a haemacytometer. The specific growth rate $(\mu)$ was calculated from the growth curve using a fitting program for the data from logarithmic growth phase. The $\mu$ was computed from the following formula (1):

$$
\mu=\ln x_{2}-\ln x_{1} /\left(t_{2}-t_{1}\right)
$$

at time $t_{1}$ and $t_{2}{ }^{11}$.

Where $X_{1}$ and $X_{2}$ are cell concentrations

The algal cells were collected every 2 days for Chlorophyll a concentration of the sample was determined according to Arnon ${ }^{12}$, Total Carotenoid concentration was determined according to Lichtenthaler ${ }^{13}$, and $\beta$-carotene analysis. To determine the $\beta$-carotene content, the samples were extracted with $80 \%$ acetone and analyzed by the reverse phase HPLC (Column: VertiSepTMBIO C30, 5um, 4.6' $250 \mathrm{~mm}$, mobile phase: Methanol/ Tertiary methyl butyl ether, $80 / 20(\mathrm{v} / \mathrm{v})$, flow rate: $1.0 \mathrm{ml} / \mathrm{min}$ ). The $\beta$-carotene was identified by its retention time and quantified by the absorbance spectra in comparison with a $\beta$-carotene standard. (Sigma)

\section{Statistical Analysis}

All the data analysis was processed by Microsoft Excel 2016 t test. The statistical significance was determined at $95 \%$ level of confidential limit.

\section{RESULTS}

Mutagenesis by UV-C and Mutant Screening

Algal colonies were initially irradiated by UV-C. Survival rate was $1 \%$ from the original 19,720 colonies. Three weeks later, only 50 colonies began to turn orange and were selected for $\beta$-carotene accumulation. The biomass productivity was calculated for $12^{\text {th }}$ days from all those selected colonies which were cultured under $1.5 \mathrm{M} \mathrm{NaCl}$ modified Johnson's medium, under light intensity of $200 \mathrm{mmol}$ photons $\mathrm{m}^{-2} \cdot \mathrm{s}^{-1}$. The highest dry weight content was achieved in KU18 (0.79 $\pm 0.02 \mathrm{~g} / \mathrm{L})$ followed by KU5 $(0.62 \pm 0.04$ $\mathrm{g} / \mathrm{L}), \mathrm{KU} 20(0.53 \pm 0.03 \mathrm{~g} / \mathrm{L})$ and KU37 (0.41 \pm 0.01 g/L) (Fig. 1). While the wild type cells still green color, the mutant cells were changed from green to orange (Fig. 2-3). High chlorophyll a, total carotenoid and $\beta$-carotene content were found in the mutants $5,18,20$ and 37 compared to the wild type strain (Table 1). KU18 provided the best pigment accumulation (Fig. 4) and the result of $\beta$-carotene accumulation ( $\mathrm{pg} / \mathrm{cell}$ ) was also the highest of the selected colonies (Fig. 5).

\section{Growth and pigment accumulation in wild type} and mutant KU18

Owing to the best ability to produce $\beta$-carotene, the $D$. salina KU18 mutant was selected for growth and pigment accumulation study. The mutant KU18 showed similar growth pattern in all three consecutive cycles of cultivation. The specific growth rate $(\mu)$ of the mutant KU18 was 0.198-0.258 which did not differ from the wild type (Table 2). The cell number gradually increased and reached the exponential phase in 6 days. The exponential phase of growth period was observed from $6^{\text {th }}-8^{\text {th }}$ days of cultivation. Growth of the

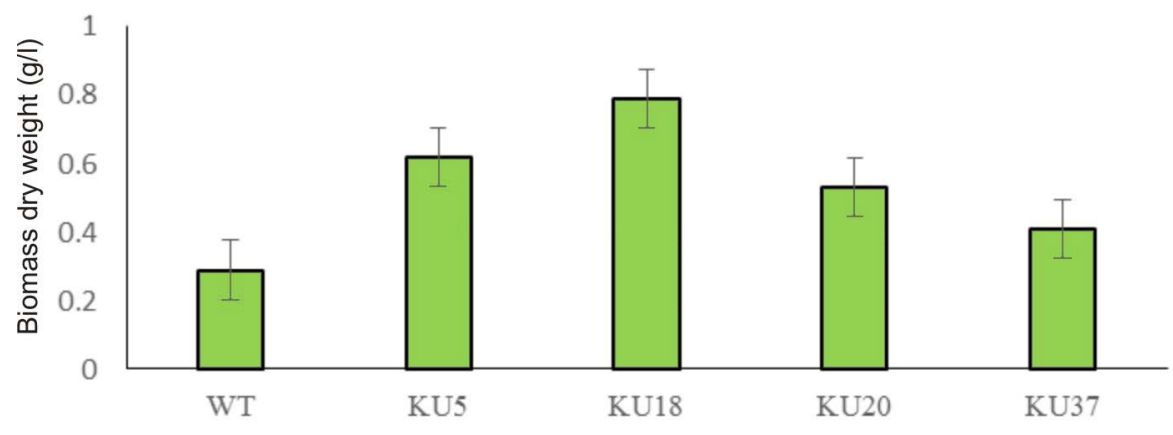

Fig. 1. Mutant screening and biomass yield of $D$. salina of each strain cultured in $1.5 \mathrm{M} \mathrm{NaCl}$ modified Johnson's medium under light intensity $200 \mathrm{mmol}$ photons $\mathrm{m}^{-2} \cdot \mathrm{s}^{-1}$. 
Table 1. Chlorophyll a, Total carotenoid and $\beta$-carotene content in the mutants $(\mathrm{mt}) 5,18,20$ and 37 at the $12^{\text {th }}$ day of cultivation, wild type (wt)

\begin{tabular}{lccccc}
\hline Isolates & wt & $\mathrm{mt} \mathrm{5}$ & $\mathrm{mt} \mathrm{18}$ & $\mathrm{mt} \mathrm{20}$ & $\mathrm{mt} \mathrm{37}$ \\
\hline Chlorophyll a $(\mathrm{mg} / \mathrm{ml})$ & $3.81 \pm 0.27$ & $12.64 \pm 0.44$ & $12.89 \pm 1.14$ & $12.02 \pm 0.58$ & $11.97 \pm 0.48$ \\
Total carotenoid $(\mathrm{mg} / \mathrm{ml})$ & $0.39 \pm 0.08$ & $2.66 \pm 0.09$ & $2.99 \pm 0.10$ & $2.35 \pm 0.27$ & $2.13 \pm 0.11$ \\
$\beta$-carotene $(\mathrm{mg} / \mathrm{ml})$ & $0.12 \pm 0.03$ & $1.74 \pm 0.11$ & $2.15 \pm 0.12$ & $1.44 \pm 0.15$ & $1.33 \pm 0.09$ \\
\hline
\end{tabular}
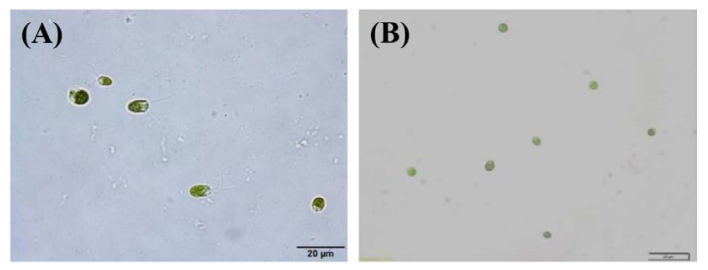

Fig. 2. D. salina $\mathrm{KU} 11$ cells grown in liquid modified Johnson's medium containing $2.5 \mathrm{M} \mathrm{NaCl}$ at $3^{\text {rd }}$ day (A) and $12^{\text {th }}$ day (B) of incubation, observed under microscope.

mutant KU18 reached stationary phase after 8 days of the cultivation (Fig. 6).

The $D$. salina mutant KU18 showed significant difference in the chlorophyll and total carotenoid ratio at all three consecutive cultivation cycles. The highest chlorophyll content was found in the culture grown in the third cultivation cycle, in which the highest chlorophyll content was 11.05 $\mu \mathrm{g} / \mathrm{ml}$. The highest total carotenoid content (mg/ $\mathrm{ml}$ ) reached the maximum content at the $12^{\text {th }}$ day
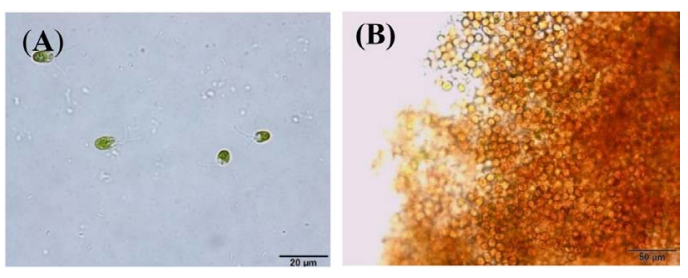

Fig. 3. D. salina mutants KU 18 cells grown in liquid modified Johnson's medium containing $2.5 \mathrm{M} \mathrm{NaCl}$ at $3^{\text {rd }}$ day $(A)$ and $12^{\text {th }}$ day $(B)$ of incubation, observed microscope

after inoculation in the third cycle of consecutive cultivation (4.72 $\mu \mathrm{g} / \mathrm{ml}, 3.84 \mathrm{pg} / \mathrm{cell}$ ) (Fig. 7 and Table 2).

In all three consecutive cycles of cultivation, the mutant KU18 accumulated 2.48.5 folds $\beta$-carotene $(\mu \mathrm{g} / \mathrm{ml}$ ) and 2.1-4.8 folds $\beta$-carotene ( $\mathrm{gg} / \mathrm{cell})$ higher than the wild type, whereas cell density of the mutant KU18 was not different from the wild type (Table 2).

Table 2. Growth and pigment production of KU18 mutant at $12^{\text {th }}$ days of cultivation. The number in brackets of mutant KU18 represents the fold numbers compared to the wild type in modified Johnson's medium containing $2.5 \mathrm{M} \mathrm{NaCl}$ under light intensity $200 \mathrm{mmol}$ photons $\mathrm{m}^{-2} \cdot \mathrm{s}^{-1}$ for 14 days.

\begin{tabular}{|c|c|c|c|c|c|c|}
\hline \multirow[t]{2}{*}{ Strain } & \multicolumn{2}{|c|}{$\begin{array}{l}1^{\text {st }} \text { cultivation } \\
\text { cycle }\end{array}$} & \multicolumn{2}{|c|}{$\begin{array}{c}2^{\text {nd }} \text { cultivation } \\
\text { cycle }\end{array}$} & \multicolumn{2}{|c|}{$\begin{array}{c}3^{\text {rd }} \text { cultivation } \\
\text { cycle }\end{array}$} \\
\hline & wt-1 & mt 18-1 & wt-2 & mt $18-2$ & wt-3 & mt $18-3$ \\
\hline Cell density (x10/cell) & 129 & $121 *$ & 118 & $113^{*}$ & 111 & $123^{*}$ \\
\hline Specific growth rate $(\mu)$ & 0.258 & $0.249 *$ & 0.200 & $0.198 *$ & 0.252 & $0.241 *$ \\
\hline Doubling time $(\mathrm{td})$ & 2.68 & $2.79 *$ & 3.47 & $3.50 *$ & 2.75 & $2.88^{*}$ \\
\hline Chlorophyll a ( $\mu \mathrm{g} / \mathrm{ml})$ & 1.03 & $5.61 *(5.4)$ & 0.54 & $6.64 *(12.3)$ & 4.12 & $11.05 *(2.7)$ \\
\hline Chlorophyll a (pg/ cell) & 0.80 & $4.56 *(5.7)$ & 3.01 & $8.30 *(2.8)$ & 3.71 & $8.99 *(2.4)$ \\
\hline Total Carotenoid( $\mu \mathrm{g} / \mathrm{ml})$ & 0.76 & $3.53 *(4.6)$ & 0.36 & $3.29 *(9.1)$ & 2.09 & $4.72 *(2.3)$ \\
\hline Total Carotenoid(pg/cell) & 0.59 & $2.87 *(4.8)$ & 2.12 & $3.96 *(1.9)$ & 1.88 & $3.84 *(2.0)$ \\
\hline$\beta$-carotene $(\mu \mathrm{g} / \mathrm{ml})$ & 0.49 & $2.20 *(4.5)$ & 0.24 & $2.04 *(8.5)$ & 1.30 & $3.06 *(2.4)$ \\
\hline$\beta$-carotene (pg/cell) & 0.38 & $1.82 *(4.8)$ & 1.12 & $2.43 *(2.2)$ & 1.17 & $2.49 *(2.1)$ \\
\hline
\end{tabular}

*Significantly different as determined by $t$ test $(a=0.05, n=3)$ 

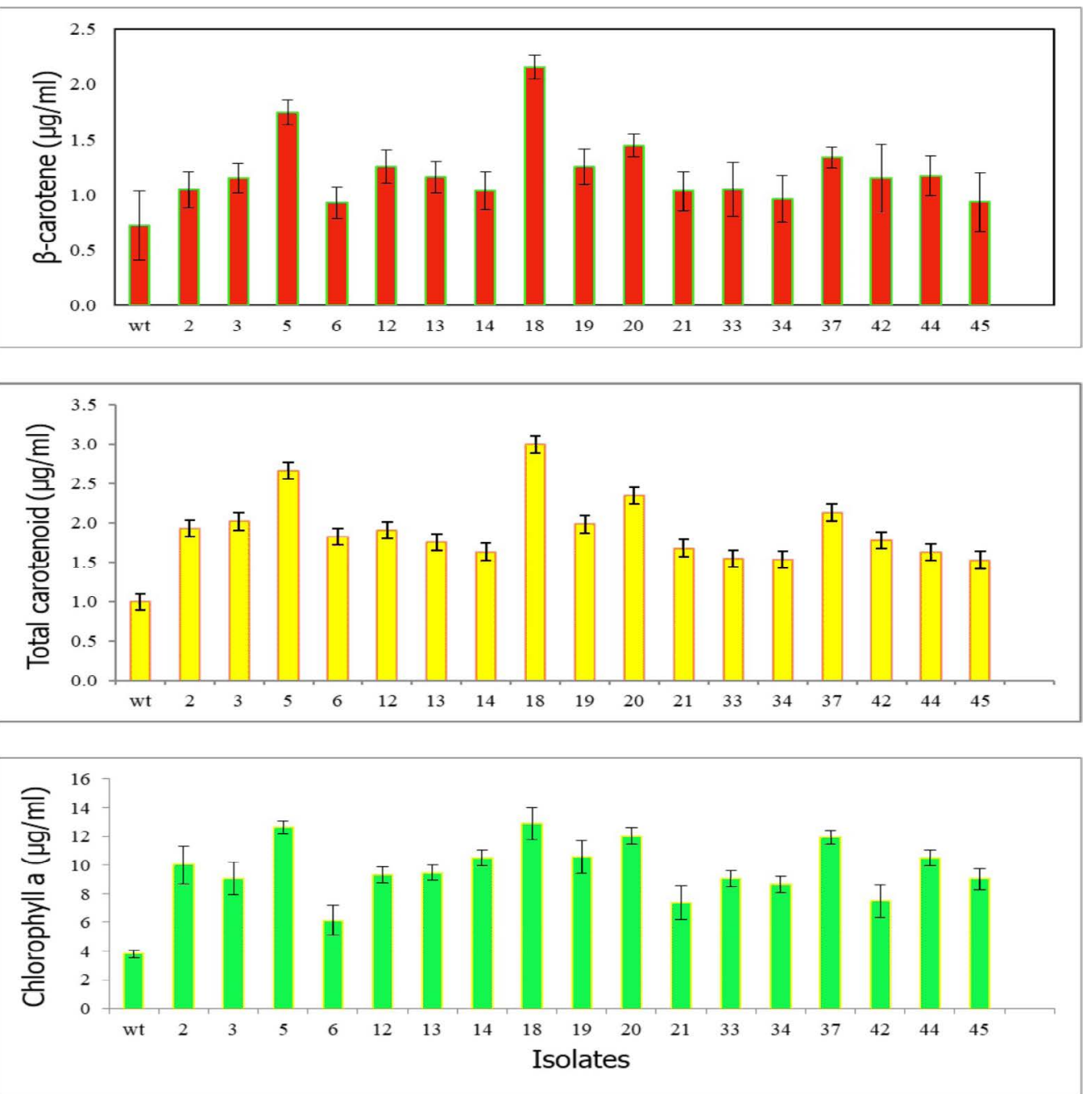

Fig. 4. Pigment concentrations of 17 selected survival mutants grown in modified Johnson's medium under light intensity $200 \mathrm{mmol}$ photons $\mathrm{m}^{-2} \cdot \mathrm{s}^{-1}$ at $12^{\text {th }}$ day of cultivation

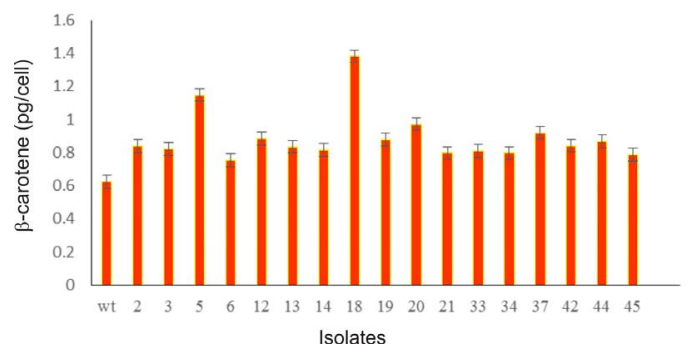

Fig. 5. Bar diagram represents $\beta$-carotene content (pg/ cell) of 17 selected survival mutants grown in modified Johnson's medium under light intensity $200 \mathrm{mmol}$ photons $\mathrm{m}^{-2} \cdot \mathrm{s}^{-1}$ at $12^{\text {th }}$ day of cultivation

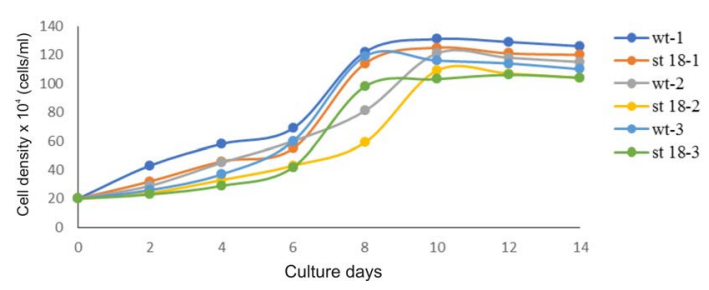

Fig. 6. Growth of wild type (wt) and mutants (mt) in the first cultivation cycle (wt-1, mt KU18-1), the second cultivation cycle (wt-2, mt KU 18-2) and the third cultivation cycle (wt-3, mt KU $18-3$ ) in $2.5 \mathrm{M} \mathrm{NaCl}$ modified Jonson's medium under $200 \mathrm{mmol}$ photons $\mathrm{m}^{-2} \cdot \mathrm{s}^{-1}$. 

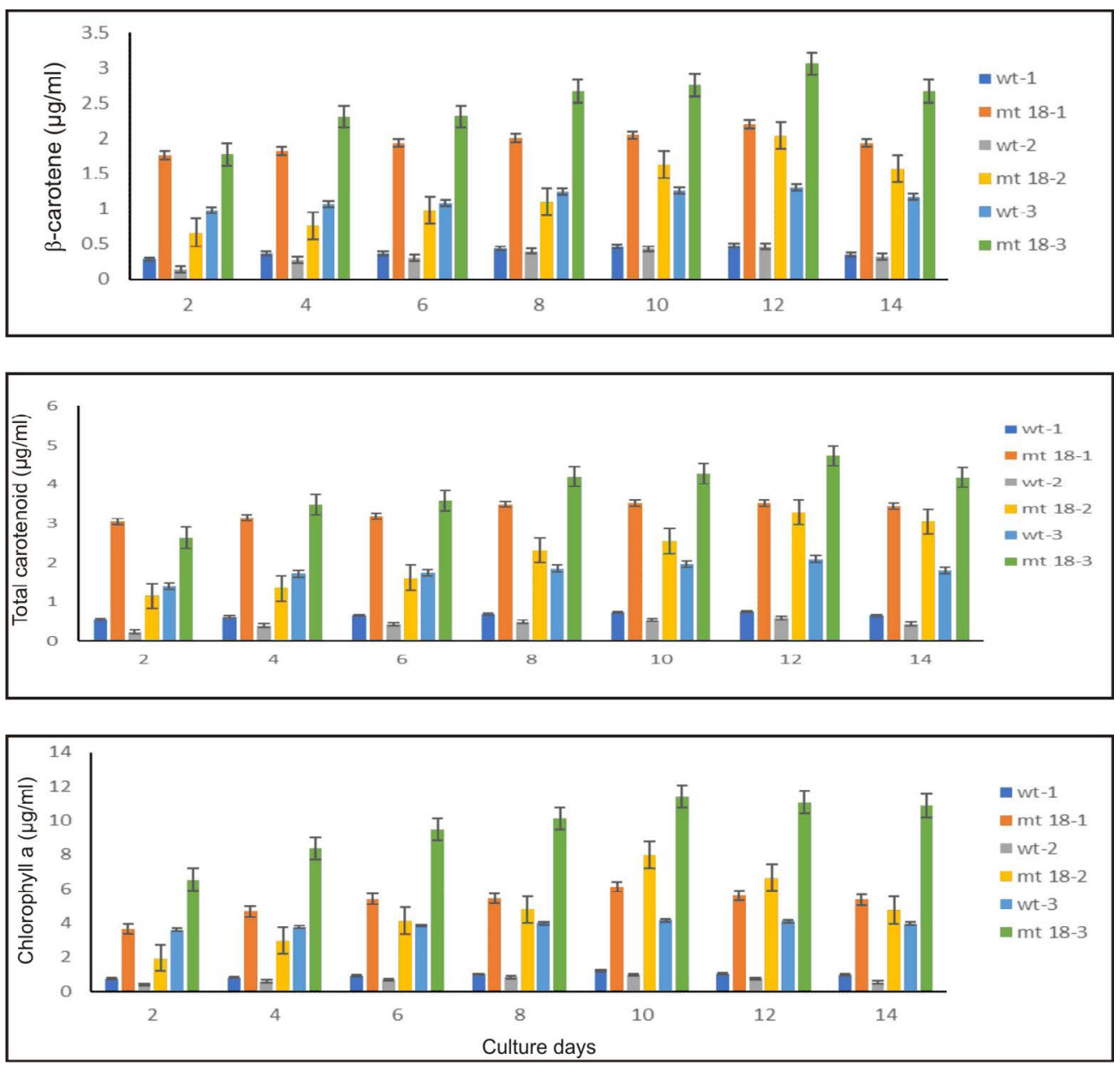

Fig. 7. Pigment of wild type and KU18 mutant strain in the first cultivation cycle (wt-1, st18-1), the second cultivation cycle (wt-2, st18-2) and the third cultivation cycle (wt-3, st18-3) in $2.5 \mathrm{M} \mathrm{NaCl}$ modified Jonson's medium under $200 \mathrm{mmol}$ photons $\mathrm{m}^{-2} \cdot \mathrm{s}^{-1}$.

\section{DISCUSSION}

This study aimed to screen $\beta$-carotene producing strains of Dunaliella salina after UV-C radiation. Growth and $\beta$-carotene production of the mutants was compared to the wild type. The result indicates that Dunaliella salina KU18 was a mutant strain because it was selected from very large populations $(19,720$ colonies) with $1 \%$ survival rate. Moreover, the KU18 produced higher total carotenoid and $\beta$-carotene than the wild type in all three consecutive cultivation cycles. However, role of the UV-C on expression of $\beta$-carotene gene was not reported in this study. Similar result was reported by Sharma et al. ${ }^{6}$, who reported that continuous UV-C radiation for $24 \mathrm{~h}$ rapidly induced carotenoid biosynthesis in $D$. salina and the total carotenoids and $\beta$-carotenoid were doubled in 24 h. UV-C has been successfully used to generate microalgae mutants ${ }^{14}$. Sirikhachornkit et al. ${ }^{8}$, found that the UV-C induced total carotenoid content of $D$. tertiolecta. UV-C played an important role on the induction of expression of genes that are encoding the antioxidant.

Nikookar et al. ${ }^{15}$, reported that plant or alga increased its chlorophyll content during stress because during stress, plant or alga cytosol contained several strong oxidative agents, such as superoxide free radical. The oxidative agents stimulated plant or alga cell to synthesis more chlorophylls and carotenoids to protect cell or 
tissue from further damage by stress conditions ${ }^{16}$. Jahns \& Holzwarth ${ }^{17}$ suggested that increasing in chlorophyll was probable a result of xanthophyll accumulation to protect photosystem II. Unlike ordinary plant which chlorophyll synthesis negatively affected by salt stress, green algae could increase chlorophyll content. However, high nitrogen concentration probably promoted chlorophyll synthesis, since pyrrole ring, a precursor in chlorophyll synthesis. Hypersaline condition also evoked oxidative stress in alga cytosol; salt stress induced synthesis of several terpene derivatives which were precursors to carotenoids and xanthophyll ${ }^{14}$.

In this study, the KU18 produced higher $\beta$-carotene in $2.5 \mathrm{M} \mathrm{NaCl}$ concentration than that in $1.5 \mathrm{M} \mathrm{NaCl}$ concentration. As reported early by Prieto et al. ${ }^{18}$, the highest $\beta$-carotene production was obtained in the $2.5 \mathrm{M} \mathrm{NaCl}$ concentration. $\beta$-carotene content affected by salinity ${ }^{19}$. They found that the highest carotenoid contents per cell were obtained when two species of $D$. salina and $D$. bardawil were cultured in media containing $2 \mathrm{M} \mathrm{NaCl}$. In the study of Radakovits et al. ${ }^{18}$, carotene contents varied from 0.2 to 11.4 $\mathrm{pg} /$ cell at the optimum concentration of $3.0 \mathrm{M}$ $\mathrm{NaCl}$. In general plant as well as algae synthesized secondary metabolites stress conditions. All plant and algae protected themselves by synthesis of terpene compounds and these terpenoids were precursors to the synthesis of carotenoids and xanthophyll ${ }^{7}$. In hypersaline condition Dunaliella could accumulate up to $14 \%$ dried weight of $\beta$-carotene. In cytosol of this algae also contained high concentration of starch, glycerol and fatty acid, in order to regulate osmotic pressure driven by salt stress. Accumulation of $\beta$-carotene as well as glycerol in cytosol was thought to be as a carbon sink in alga cell ${ }^{2,6,20}$. Moreover, Dunaliella was sensitive to UV radiation and UV which increased production of fat, oil and b-carotene ${ }^{12,21,22,23}$.

The mutant KU18 accumulated 1.38 and $2.49 \mathrm{pg} \beta$-carotene/cell in the medium containing 1.5 and $2.5 \mathrm{M} \mathrm{NaCl}$, respectively (Figure 5 and Table 2). To test for the $\beta$-carotene accumulation efficiency between the mutant KU18 and the wild type strain, the light intensity was limited to $200 \mathrm{mmol}$ photons $\mathrm{m}^{-2} \cdot \mathrm{s}^{-1}$. Under this condition, the accumulation efficiency of $\beta$-carotene in the mutant KU18 is more effective than that in the wild type strain. Similarly, Kim et al. ${ }^{1}$, reported that development of a Dunaliella tertiolecta Strain with increased $\beta$-carotene content using random mutagenesis under light intensity $160 \mu \mathrm{mol}$ photons $\mathrm{m}^{-2} \mathrm{~s}^{-1}$.

\section{CONCLUSION}

The $0.4 \mathrm{mmol}$ photons $\mathrm{m}^{-2} \cdot \mathrm{s}^{-1} \mathrm{UV}-\mathrm{C}$ was successfully used to induce mutation of $D$. salina KU11 strain with the increase in $\beta$-carotene production. The mutant was proved to be sustained. In all three consecutive cultivation cycles, the $\beta$-carotene content in the $D$. salina mutant KU18 remained higher than the wild type strain.

\section{ACKNOWLEDGMENTS}

This research was supported from graduate scholarship provided by the National Research Council of Thailand (NRCT) as of fiscal year 2017. This work was also supported by the Graduate School as well as the Faculty of Science, Kasetsart University, Faculty of Science and Fisheries Technology, Rajamangala University of Technology, Srivijaya, Trang Campus and the Faculty of Science Mahidol University for the supports on analytical instruments and workplaces. The authors also thank Wattanapong Sittisaree, Rungdawan Wongsamart and Somchoke Traewachiwiphak for technical assistance.

\section{CONFLICT OF INTEREST}

The authors declares that there is no conflict of interest.

\section{REFERENCES}

1. Kim, M., Ahn, J., Jeon, H. \& Jin, E. Development of a Dunaliella tertiolecta strain with increased zeaxanthin content using random mutagenesis. Marine Drugs. 2017; 15:189-201

2. Guedes, A. C., Amaro, H. M. \& Malcata, F. X. Microalgae as sources of carotenoids. Marine Drugs. 2011; 9:625-644.

3. Sathasivam, R.\& Ki, J.S. A Review of the Biological Activities of Microalgal Carotenoids and Their Potential Use in Healthcare and Cosmetic Industries. Marine Drugs. 2018; 16:26.

4. Garcia-Gomez, C., Parages, M.L., Jimenez, C., Palma, A., Mata, M.T. \& Segovia, M. Cell survival after UV radiation stress in the unicellular chlorophyte Dunaliella tertiolecta is mediated by 
DNA repair and MAPK phosphorylation.Journal of Experimental Botany. 2012; 63:5259-5274.

5. Gao,Y., Cui, Y., Xiong, W., Li, X. \& Wu, Q. Effect of UV-C on algal evolution and differences in growth rate, pigmentation and photosynthesis between prokaryotic and eukaryotic algae. Photochemistry and Photobiology. 2009; 85:774-782.

6. Sharma, K.K., Ahmed, F., Schenk, P.M. \& Li, Y. UV-C Mediated Rapid Carotenoid Induction and Settling Performance of Dunaliella salina and Haematococcus pluvialis. Biotechnology and Bioengineering. 2015; 112:10.

7. Lim, D.K.Y., Schuhmann, H., Sharma, K. \& Schenk, P.M. Isolation of high-lipid Tetraselmis suecica strains following repeated UV-C mutagenesis, facs, and high-throughput growth selection. Bioenergy Research. 2015; 8:750-759.

8. Sirikhachornkit, A., Vuttipongchaikij, S., Suttangkakul, A., Yokthongwattana, K., Juntawong, P., Pokethitiyook, P., Meetam, M. Increasing the triacylglycerol content in Dunaliella tertiolecta through isolation of starchdeficient mutants. Journal of Microbioogy. Biotechnoogy. 2016; 26:854-866.

9. Masi, A. \& Melis, A. Morphological and molecular changes in the unicellular green alga Dunaliella salina grown under supplemental UV-B radiation: cell characteristics and Photosystem II damage and repair properties. Biochimicaet Biophysica Acta (BBA) Bioenergetics. 1997; 1321:183-193.

10. Borowitzka, M.A. Vitamin and fine chemical from micro-algae. In M.A.Borowitzka \& L.J. Borowitzka (Eds.). Micro-algal Biotechnology. 1988; 13:165174.

11. Vonshak, A. Microalgae : Laboratory Growth Techniques and Outdoor Biomass Production. In J. Coombs,D.O. Hall, S.P. Long and J.M.O. Scurlock (Eds.). Techniques in Bioproductivity and Photosynthesis. 1985; 188-200.

12. Arnon, D. Copper enzymes in isolated chloroplasts. Polyphenol oxidase in Beta vulgaris. Plant Physiology. 1949; 24:1-5.

13. Lichtenthaler, H.K. Chlorophyll and carotenoids: pigments of photosynthetic biomembranes. Methods in Enzymology.1987; 148:349-382.

14. Kamath, S.B., Vidhyavathi, R., Sarada, R. \&
Ravishankar, G.A. Enhancement of carotenoids by mutation and stress induced carotenogenic genes in Haema-tococcus pluvialis mutants. Bioresource Technology. 2008; 99:8667-8673.

15. Nikookar, K., Moradshahi, A. \& Hosseini, L. Physiological responses of Dunaliella salina and Dunaliella tertiolecta to copper toxicity. Biomolecular Engineering. 2005; 22:141-146.

16. Yilancioglu, K., Cokol, M., Pastirmaci, I., Erman, B. \& Cetiner, S. Oxidative stress is a mediator for increased lipid accumulation in a newly isolated Dunaliella salina strain. PLOSONE. 2014; 9:1-13.

17. Jahns, P. \& Holzwarth, A.R. The role of the xanthophyll cycle and of lutein in photoprotection of photosystem II. Biochimica et Biophysica Acta. 2012; 1817:182-193.

18. Prieto, A., Canavatea, J.P. \& Gonzalezb, M.G Assessment of carotenoid production by Dunaliella salina in different culture systems and operation regimes. Journal of Biotechnology. 2011; 151:180-185.

19. Gomez, P.I., Barriga, A., Cifuentes, A.S. \& Gonzalez, M.A. Effect of salinity on the quantity and quality of carotenoids accumulated by Dunaliella salina (strain CONC-007) and Dunaliella bardawil (strain ATCC 30861) Chlorophyta. Biological Research. 2003; 36:185-192.

20. Radakovits, R., Jinkerson, R.E, Darzins, A. \& Posewitz, M.C. Genetic engineering of algae for enhanced biofuel production. Eukaryotic Cell, 2010; 9:486-501.

21. Srinivas, R. \& Ochs, C. Effect of UV-A Irradiance on Lipid Accumulation in Nanno-chloropsis oculate.Photochemistry and Photobiology. 2012; 88:684-689.

22. Mogedas, B., Casal, C., Forjan, E. \& Vilchez, C. $\beta$-Carotene production enhancement by UV-A radiation in Dunaliella bardawil cultivated in laboratory reactors. Journal of Bioscience and Bioengineering. 2009; 108:47-51.

23. Salguero, A., Leon, R., Mariotti, A., Morena, B., Vega, J.M. \& Volchez, C. UV-A mediated induction of carotenoid accumulation in Dunaliella bardawil with retention of cell viability. Applied Microbiology and Bio-technology. 2005; 66:506511. 